\title{
Hepatocyte Growth Factor-Met Signaling Is Required for Runx1 Extinction and Peptidergic Differentiation in Primary Nociceptive Neurons
}

\author{
Eduardo Gascon, ${ }^{1 \star}$ Stéphane Gaillard, ${ }^{1 \star}$ Pascale Malapert, ${ }^{1}$ Yang Liu, ${ }^{2}$ Lise Rodat-Despoix,${ }^{4}$ Igor M. Samokhvalov, ${ }^{3}$ \\ Patrick Delmas, ${ }^{4}$ Françoise Helmbacher, ${ }^{1}$ Flavio Maina, ${ }^{1}$ and Aziz Moqrich ${ }^{1}$ \\ ${ }^{1}$ Institut de Biologie du Développement de Marseille Luminy, Unite Mixte de Recherche (UMR) 6216, Centre National de la Recherche Scientifique (CNRS)- \\ Université de la Méditerranée, 13288 Marseille, France, ${ }^{2}$ Dana-Farber Cancer Institute and Department of Neurobiology, Harvard Medical School, Boston, \\ Massachusetts 02115, ${ }^{3}$ Laboratory for Stem Cell Biology, Center for Developmental Biology, RIKEN Kobe, Chuo-ku, Kobe, 650-0047 Japan, ${ }^{4}$ Centre de \\ Recherche en Neurobiologie et Neurophysiologie de Marseille, UMR 6231, CNRS, Université de la Méditerranée, 13344 Marseille, France
}

Nociceptors in peripheral ganglia display a remarkable functional heterogeneity. They can be divided into the following two major classes: peptidergic and nonpeptidergic neurons. Although RUNX1 has been shown to play a pivotal role in the specification of nonpeptidergic neurons, the mechanisms driving peptidergic differentiation remain elusive. Here, we show that hepatocyte growth factor (HGF)-Met signaling acts synergistically with nerve growth factor-tyrosine kinase receptor A to promote peptidergic identity in a subset of prospective nociceptors. We provide in vivo evidence that a population of peptidergic neurons, derived from the RUNX1 lineage, require Met activity for the proper extinction of Runx 1 and optimal activation of CGRP (calcitonin gene-related peptide). Moreover, we show that RUNX1 in turn represses Met expression in nonpeptidergic neurons, revealing a bidirectional cross talk between Met and RUNX1. Together, our novel findings support a model in which peptidergic versus nonpeptidergic specification depends on a balance between HGF-Met signaling and Runx1 extinction/maintenance.

\section{Introduction}

Sensory neurons of the dorsal root ganglia (DRG) detect and transduce somatosensory stimuli from the periphery and convey this information to the spinal cord. Most sensory neurons arise from neural crest cells that migrate ventrally to form the DRG (White et al., 1996; Raible and Ungos, 2006; Marmigère and Ernfors, 2007). Neuronal precursors in the ganglion undergo the first specification process [embryonic day (E) 10.5-E13.5 in the mouse] that gives rise to the three principal neuronal subtypes: nociceptive-thermoceptive, mechanoceptive, and proprioceptive neurons. Each neuronal population requires a specific neurotrophic support for proper survival and expresses distinct neurotrophin receptors of the Trk family (Lewin, 1996; Patapoutian and Reichardt, 2001). After this early diversification event, a second maturation step further expands

\footnotetext{
Received June 18, 2010; accepted July 22, 2010.

This work was supported by grants from Centre National de la Recherche Scientifique: Action Thématique et Incitative sur Programme, Agence Nationale pour la Recherche (ANR-Neuro-2006) (to A.M.), Fondation pour le Recherche Médicale (to E.G.), and Association Française contre les Myopathies (to F.M.). We thank A. Patapoutian, J. Ewbank, and Q. Ma for comments on the manuscript, F. Lamballe and M. Genestine for kindly providing mice, S.S Thorgeirsson for the met ${ }^{f l / f f x}$ mice, Tom Jessell and Louis Reichardt for the RUNX1 and TrkA antibodies, and Prof. A. Friedman for the human Runx1 plasmid. E.G., S.G., and A.M. conceived the experiments; E.G. and S.G. performed all the experiments; P.M., Y.L., P.D., L.R.-D., I.M.S., F.H., and F.M. provided intellectual, technical, and logistical contribution; and E.G., S.G., and A.M. cowrote the paper.

${ }^{*} E$.G. and S.G. contributed equally to this work.

The authors declare no competing financial interests.

Correspondence should be addressed to Aziz Mogrich, Institut de Biologie du Développement de Marseille Luminy, Unite Mixte de Recherche 6216, Centre National de la Recherche Scientifique-Université de la Méditerranée, Campus de Luminy Case 907, 13288 Marseille Cedex 09, France. E-mail: moqrich@ibdml.univ-mrs.fr.

D0I:10.1523/JNEUROSCI.3135-10.2010

Copyright $\odot 2010$ the authors $\quad 0270-6474 / 10 / 3012414-10 \$ 15.00 / 0$
}

the heterogeneity within each population. In nociceptive neurons, this phase is characterized by the progressive segregation of tyrosine kinase receptor A (TrkA) neurons into two subpopulations: peptidergic neurons that retain the expression of TrkA receptor and signal through nerve growth factor (NGF); and nonpeptidergic neurons that extinguish TrkA and respond to glial cell-derived neurotrophic factor-Ret signaling (Molliver et al., 1997; Ibáñez and Ernfors, 2007; Luo et al., 2007; Woolf and Ma, 2007).

Recent work has given new insights into the molecular control of late nociceptive maturation. A number of studies provided genetic evidence that persistent expression of the transcription factor RUNX1 is the key event for prospective nociceptors to undergo nonpeptidergic differentiation (Chen et al., 2006; Kramer et al., 2006b; Marmigère et al., 2006; Woolf and Ma, 2007; Yoshikawa et al., 2007). However, it is still unclear whether the peptidergic phenotype is the default differentiation pathway in prospective nociceptive neurons devoid of RUNX1 or, rather, an active process of cell fate choice. Given that the population of RUNX1 ${ }^{-}$prospective nociceptors $(\sim 10 \%$ of the total population) cannot account for the number of peptidergic neurons observed in the adult DRG (25\% of the total population) (Chen et al., 2006), it has been proposed that a subset of RUNX1 ${ }^{+}$progenitors actively turn off Runx 1 expression and acquire peptidergic identity (Woolf and Ma, 2007). In agreement with this hypothesis, it has been shown that expression of some ion channels of the transient receptor potential (TRP) family, normally expressed in adult peptidergic neurons, is lost in the absence of Runxl. These observations strongly suggest that peptidergic neurons (or at least, a subset of them) derive from Runx ${ }^{-}$-expressing precursors. 

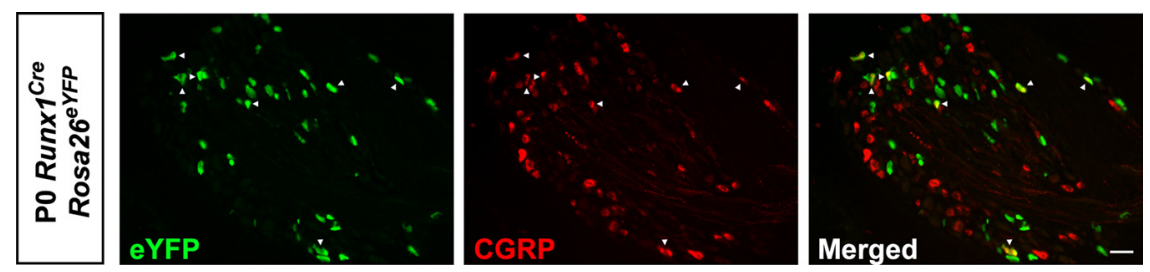

Figure 1. A population of $\mathrm{CGRP}^{+}$peptidergic neurons arises from $\mathrm{RUNX1}^{+}$precursors. Fate-mapping analysis of RUNX1 lineage using tamoxifen-inducible Runx $7^{\text {(re }}$. Representative examples of CGRP and YFP immunofluorescence in newborn DRG of Runx $1^{\text {Cre }}$ Rosa2 $6^{\text {eYFP }}$ injected with 4-0HT at E12.5. These lineage experiments clearly demonstrated that a number of (GRP ${ }^{+}$ peptidergic neurons (arrowheads) derive from cells expressing RUNX1 at early developmental stages. Scale bars, $20 \mu \mathrm{m}$.

How is Runx1 expression controlled during nociceptive segregation? Recent work demonstrated that NGF signaling is necessary for the maintenance of Runx1 in nonpeptidergic nociceptive neurons (Luo et al., 2007). Since both peptidergic and nonpeptidergic neurons require NGF for proper development (Smeyne et al., 1994), these observations strongly suggest that additional factor(s), in concert with NGF, ensure the extinction of Runxl in a subset of prospective peptidergic neurons. However, the molecular identity of such factor(s) has remained elusive.

Here, we provide the first in vivo evidence that a subset of peptidergic nociceptive neurons do derive from the RUNX1 lineage. We also identify a novel regulatory mechanism involving an active repressive loop between Met and RUNX1 that specifies the molecular identity of this subpopulation of nociceptive neurons. We show that, in conditional Met knock-out mice, a subset of prospective peptidergic neurons is no longer able to extinguish Runx1, leading to incomplete segregation of RUNX1 from TrkA ${ }^{+}$ neurons. The consequence of this RUNX1 persistence is the loss of several peptidergic markers, including CGRP, TRPV1, and TRPA1, as well as the expansion of the intermediate population of neurons expressing both TrkA and Ret. Conversely, disruption of Runx1 expression in the peripheral nervous system resulted in a massive deregulation of Met and impaired maturation of nonpeptidergic neurons, arguing that persistent expression of RUNX1 is necessary to repress Met and instruct nonpeptidergic differentiation. Collectively, our findings indicate that Met/RUNX1 cross talk is a key event in the molecular logic of primary sensory neuronal diversification, thereby extending our understanding of nociceptive diversification.

\section{Materials and Methods}

Animals. We first introduced the $M e t^{d}$ allele [in which the mutation of two key tyrosine residues renders Met receptor functionally inactive (Ponzetto et al., 1994)] into a mouse strain expressing Cre recombinase under nestin promoter (Nestin-Cre mice) (Isaka et al., 1999; Kramer et al., 2006b; Zhong et al., 2007) to obtain $\mathrm{Met}^{\mathrm{d} /+} ; \mathrm{Nes}-\mathrm{Cre}^{+}$animals. These animals were then crossed to previously described Met $t^{f l / f l x}$ mice [in which two loxP sites flank Met exon 16 (Huh et al., 2004)], kindly provided by Dr. Snorri S. Thorgeirsson (National Cancer Institute, National Institutes of Health, Bethesda, MD). Mice obtained from that breeding were tail genotyped using Cre-, Met ${ }^{d}$-, and $\mathrm{Met}^{f l x}$-specific primers. Conditional Met knock-out animals $\left(\mathrm{Met}^{f \mathrm{fl} / \mathrm{d}}\right.$; Nes-Cre ${ }^{+}$, called Nes-Met) and control littermates (Met ${ }^{f l x / d}$;Nes-Cre $e^{-}$, called control) were used for all analysis. Runxl mutant animals were a generous gift from Dr. Ma (Dana Farber Cancer Institute, Boston, MA) and have been previously characterized (Chen et al., 2006). Run $x 1^{\text {Cre }}$ mice were provided by Dr. I.M. Samokhvalov (RIKEN Kobe, Kobe, Japan) and have been described previously (Samokhvalov et al., 2007). Runx1-LacZ animals were a generous gift from Dr. Nancy A. Speck (University of Pennsylvania, Philadelphia, PA) and have been previously described (North et al., 1999). Animals were maintained under standard housing conditions $\left(25^{\circ} \mathrm{C}, 40 \%\right.$ humidity, $12 \mathrm{~h}$ light cycles, and free access to food and water). Special effort was made to minimize the number as well as the stress and suffering of mice used in this study. All protocols are in agreement with European Union recommendations for animal experimentation.

In situ hybridization and immunofluorescence. In situ hybridization and immunofluorescence were performed following standard protocols (Moqrich et al., 2004). To obtain adult tissues, animals were deeply anesthetized with a mix of ketamine/xylazine and then transcardially perfused with an ice-cold solution of paraformaldehyde $4 \%$ in PBS (PAF). After dissection, they were postfixed for at least $24 \mathrm{~h}$ in the same fixative. Embryos were collected in ice-cold PBS, gently washed, and fixed for $48 \mathrm{~h}$ in $4 \%$ PAF. For skin immunofluorescence, trunk skin was excised from anesthetized animals and fixed directly in $15 \%(\mathrm{v} / \mathrm{v})$ acid picric-2\% formaldehyde for $16 \mathrm{~h}$. Tissues were then transferred into a $30 \%(\mathrm{w} / \mathrm{v})$ sucrose solution for cryoprotection before being frozen and stored at $-80^{\circ} \mathrm{C}$. Samples were sectioned using a standard cryostat (Leica).

RNA probes were synthesized using gene-specific PCR primers and cDNA templates from embryonic or adult mouse DRG. Double-fluorescent in situ hybridization was performed using a combination of digoxigenin and fluorescein/biotin-labeled probes. Probes were hybridized overnight at $55^{\circ} \mathrm{C}$, and the slides incubated with the horseradish peroxidase anti-digoxigenin/fluorescein/biotin antibody (Roche). Final detection was achieved using fluorescein/cy3/cy5 TSA plus kit (PerkinElmer). For double-fluorescent in situ experiments, the first antibody was inactivated using $\mathrm{H}_{2} \mathrm{O}_{2}$ treatment.

For immunofluorescence, primary antibodies were diluted in PBS$10 \%$ donkey serum (Sigma)-3\% bovine albumin (Sigma)-0.4\% Triton $\mathrm{X}-100$ and incubated overnight at $4^{\circ} \mathrm{C}$. Corresponding donkey antirabbit or anti-goat Alexa 488, 555, or 647 (Invitrogen) were used for secondary detection. Primary antibodies used in this study are as follows: rabbit anti-TrkA 1:1000 (generous gift from Dr. L. Reichardt, University of California, San Francisco, CA), rabbit anti-Runx1 1:4000 (generous gift from Dr. T. Jessell, New York University School of Medicine, New York, NY), rabbit anti-activated caspase-3 1:2000 (Cell Signaling Technology), goat anti-TrkC 1:500 (R\&D Systems), goat anti-Ret 1:500 (R\&D Systems), rabbit anti-calcitonin gene-related peptide (CGRP) 1:1000 (Millipore Bioscience Research Reagents), chicken anti-green fluorescent protein (GFP) 1:1000 (Aves Labs), and goat anti-parvalbumin 1:2000 (Swant).

DRG cultures, transfection, and growth factors. DRG cultures were prepared following standard protocols. Briefly, DRG from embryonic day (E) 14.5 embryos were collected in cold DMEM. After trypsinization (10 $\min$ at $37^{\circ} \mathrm{C}$ ), tissue was triturated using a fire-polished Pasteur pipette. Cells were then rinsed in Roswell Park Memorial Institute (RPMI) medium and counted before transfection.

DRG neurons were transfected using Amaxa Nucleofection. For each transfection reaction, $5 \times 10^{5}$ cells were used. To limit cell death after transfection, a recovery step ( 15 min in RPMI medium) was performed. Cells were then plated onto $35 \mathrm{~mm}$ dishes coated with poly-L-lysine (Sigma) containing pre-equilibrated culture medium. Cells were grown in Neurobasal (Invitrogen) supplemented with 2\% B27 (Invitrogen) and $100 \mu \mathrm{M}$ sodium pyruvate. Culture medium was replaced 2 and $24 \mathrm{~h}$ after transfection.

Plasmid containing the human Met was provided by Professor C. Ponzetto (University of Turin, Turin, Italy). For nucleofection, $1 \mu \mathrm{g}$ of plasmid DNA/reaction was used.

Exogenous growth factors were added to the culture medium immediately after transfection. Recombinant NGF was purchased from Alomone Labs, and hepatocyte growth factor (HGF) from R\&D Systems.

Reverse transcription-PCR. RNA was extracted (embryonic or adult DRG, PC12, and DRG cultures) using TriZol reagent (Invitrogen) according to manufacturer's protocol. Total RNA $(1 \mu \mathrm{g})$ was converted to cDNA using oligodT $\mathrm{T}_{15}$ as primer and ImPromII reverse transcriptase (Promega). Reverse transcription was performed for $1 \mathrm{~h}$ at $42^{\circ} \mathrm{C}$.

For PCR, GoTaq polymerase (Promega) and a standard thermal cycler (Applied Biosystems) were used. Real-time PCR was performed in an iCycler system (Bio-Rad). PCRs were performed in triplicate using SYBR Green ER reagent system (Invitrogen). Each SYBR Green reaction ( $25 \mu$ l total volume) 
a
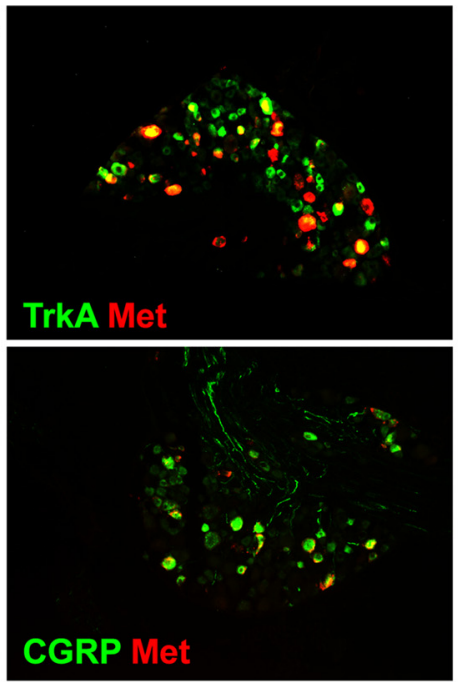
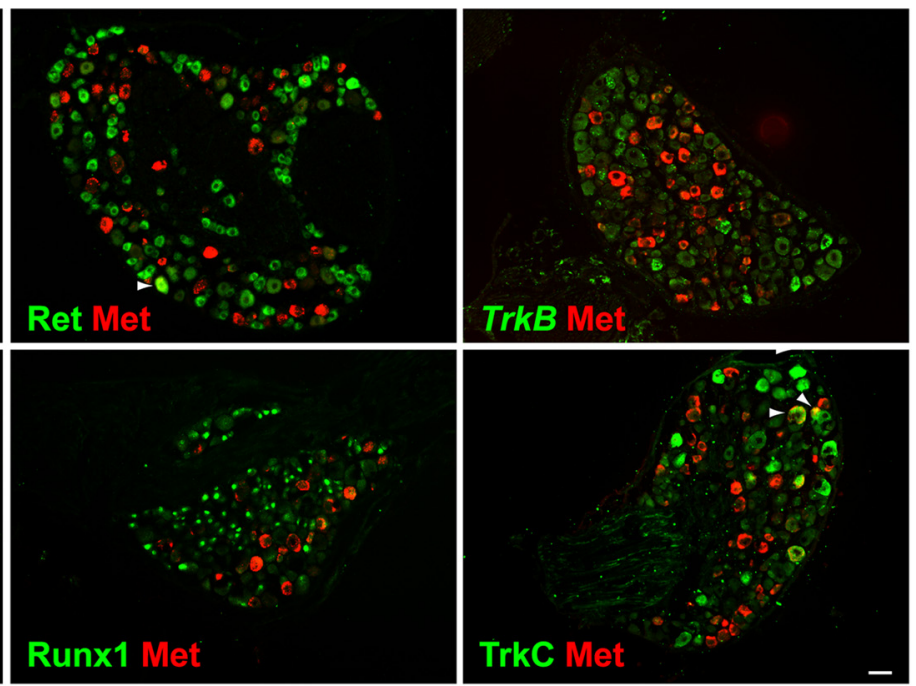

b

\begin{tabular}{|c|c|c|c|c|c|c|}
\hline Marker & TrkA & TrkB & TrkC & CGRP & Ret & PV \\
\hline $\begin{array}{c}\% \text { of Met }{ }^{+} \text {neurons } \\
\text { expressing marker }\end{array}$ & $73.5 \pm 3.8 \%$ & $1.6 \pm 1.5 \%$ & $4.8 \pm 0.2 \%$ & $82.2 \pm 6.6$ & $6.2 \pm 4.2 \%$ & $18.1 \pm 5.3 \%$ \\
\hline $\begin{array}{c}\text { \% of Marker }{ }^{+} \text {neurons } \\
\text { expressing Met }\end{array}$ & $43.2 \pm 6.1 \%$ & $1.2 \pm 0.9 \%$ & $18.6 \pm 1.5 \%$ & $55.5 \pm 3.1 \%$ & $4.6 \pm 1.2 \%$ & $27 \pm 4.7 \%$ \\
\hline
\end{tabular}

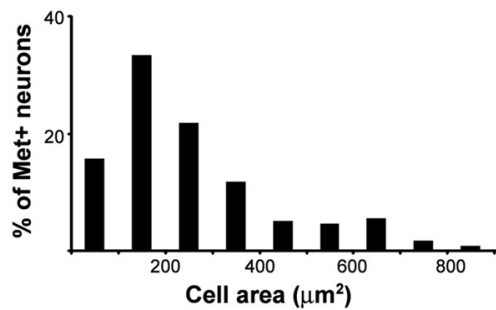

C
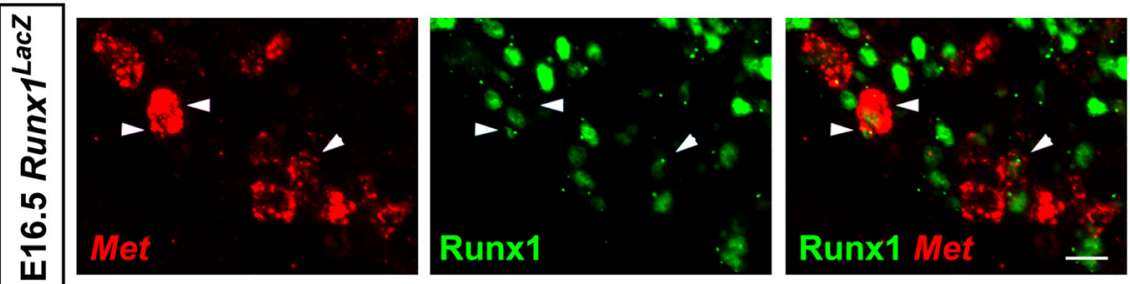

Figure 2. Met is expressed in a subset of adult DRG neurons. $\boldsymbol{a}$, Pictures of adult DRG illustrating double labeling of Met together with different markers of specific neuronal populations. As shown, most $\mathrm{Met}^{+}$neurons are $\mathrm{TrkA}^{+} / \mathrm{CGRP}^{+}$peptidergic neurons. It is also expressed in some TrkC ${ }^{+}$neurons (arrowheads). In contrast, Met is largely excluded from Ret ${ }^{+} / \mathrm{RUNX}^{+}{ }^{+}$population of nociceptive neurons and TrkB ${ }^{+}$mechanoceptive neurons. Immunofluorescence for CGRP, TrkA, TrkC, Ret, and RUNX1. In situ hybridization for Met and TrkB. $\boldsymbol{b}$, Proportions of Met ${ }^{+}$cells expressing different markers (data obtained from three different animals) and size distribution of Met ${ }^{+}$neurons. c, Pictures illustrating coexpression of Met and RUNX1 at E16 in Runx $1^{\text {LacZ }}$ reporter embryos. Immunoflurescence for LacZ. In situ hybridization for Met. Scale bars: $\boldsymbol{a}, 50 \mu \mathrm{m} ; \boldsymbol{b}, 30 \mu \mathrm{m}$.

contained $1 \mu \mathrm{l}$ of cDNA as template and $0.3 \mu \mathrm{M}$ each primer. Controls without template DNA (water and reverse transcription reaction) were always negative. The reactions were incubated at $95^{\circ} \mathrm{C}$ for $10 \mathrm{~min}$ to activate the HotStar Taq polymerase followed by 40 cycles at $95^{\circ} \mathrm{C}$ for $15 \mathrm{~s}$ (denaturation) and at $60^{\circ} \mathrm{C}$ for $1 \mathrm{~min}$ (annealing and extension). $\beta$-Actin was used as internal control. The oligonucleotide primers used for PCR were shown in supplemental Table 1 (available at www.jneurosci.org as supplemental material).

Because SYBR Green indiscriminately binds to double-stranded DNA, other products in the PCR such as primer dimers may be detected along with the target gene. To verify that the SYBR Green dye detected only one PCR product, the samples were subjected to the heat dissociation protocol after the final cycle of the PCR.

Cell counts and statistical analysis. For adult tissues, we adopted a strategy that has been previously validated for DRG cell counts (Chen et al., 2006). Briefly, serial sections of thoracic DRG were distributed on six slides, which were subjected to different markers including the panneuronal marker SCG10. This approach allowed us to refer all countings to the total number of neurons $\left(S C G 10^{+}\right)$. For each genotype, two to four DRG were counted in at least three independent animals. For embryonic tissues, after counting the total number of neurons expressing a certain marker, we related that figure to the number of sections. All cell counts were conducted by an individual who was blind to the experimental condition of the animals. Statistical significance was set to $p<0.05$ and assessed using one-way ANOVA followed by unpaired $t$ test (all other experiments).

Cell lines and transfection. PC12 cells were cultured in DMEM supplemented with $10 \%$ fetal calf serum (FCS) and 5\% horse serum. The day before transfection cells were trypsinized and cells plated onto $5 \mathrm{~cm}$ dishes [for quantitative reverse transcription (RT)-PCR; $5 \times 10^{5}$ cells] or six well plates (for luciferase assays; $2 \times 10^{5}$ cells) coated with polyornithine. Transfection was performed using Lipofectamine reagent and Opti-MEM medium (Invitrogen) following the manufacturer's instructions. After $6 \mathrm{~h}$, transfection complexes were removed and cells cultured overnight in DMEM with no serum

To test Met overexpression, HEK cells were cultured in DMEM-10\% FCS. The day before transfection, they were plated onto $10 \mathrm{~cm}$ dishes. This cell line was transfected using Promofectin reagent (PromoKine) following the manufacturer's instructions.

For treatment with exogenous growth factors, cells were starved overnight in serum-free medium and the next day recombinant NGF (Alomone Labs), HGF (R\&D Systems), EGF (R\&D Systems), and FGF8 (R\&D Systems) were added to the medium.

Western blot. HEK cells were first homogenized in ice-cold disruption buffer $(20 \mathrm{~mm}$ Tris- $\mathrm{HCl}, \mathrm{pH}$ 7.4, $10 \mathrm{~mm} \mathrm{NaCl}, 10 \mathrm{~mm} \mathrm{KCl}, 3 \mathrm{~mm}$ 
a
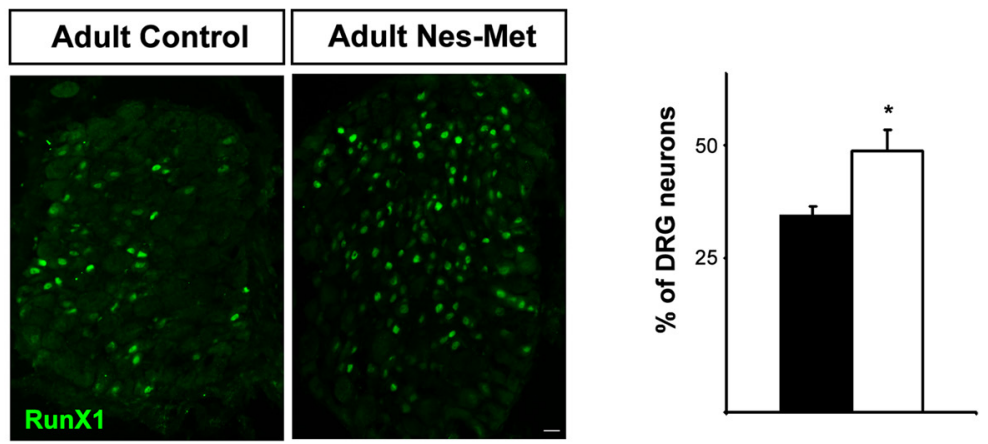

- Control

$\square$ Nes-Met

b
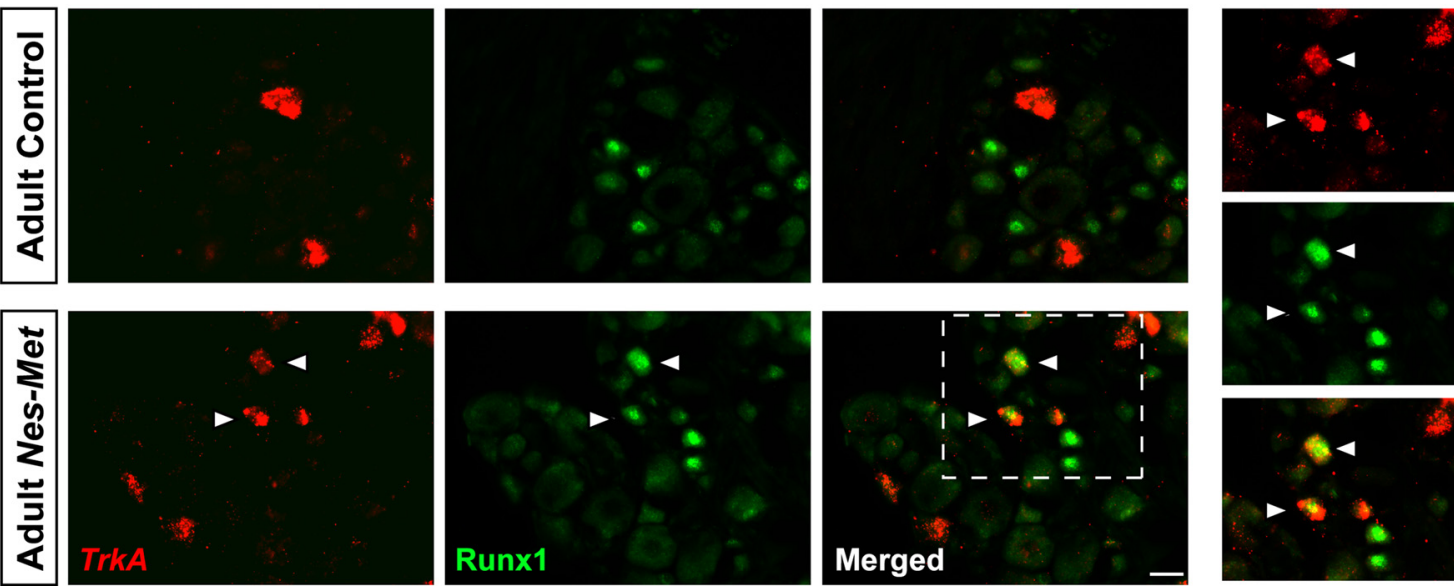

Figure 3. Met controls Runx1 extinction in vivo. $\boldsymbol{a}$, Increased number of RUNX1 neurons in Nes-Met mutant animals. Pictures of RUNX1 immunofluorescence show a moderate increase of RUNX1 ${ }^{+}$ neurons in Nes-Met mice. Quantitative analysis revealed a significant difference in these animals compared with control ( ${ }^{*} p<0.05$; control, $n=3$; Nes-Met, $n=3$ ). $\boldsymbol{b}$, Persistent expression of RUNX1 in TrkA ${ }^{+}$neurons in adult Nes-Met mice. TrkA in situ hybridization followed by immunofluorescence for RUNX1 revealed that RUNX1 is completely excluded from peptidergic neurons in control animals (top). In contrast, a number of TrkA ${ }^{+}$neurons maintains RUNX1 expression in adult Nes-Met mice (bottom) suggesting that Met is necessary for proper Runx 1 extinction. Immunofluorescence for RUNX1. In situ hybridization for TrkA. Scale bars, $20 \mu \mathrm{m}$.
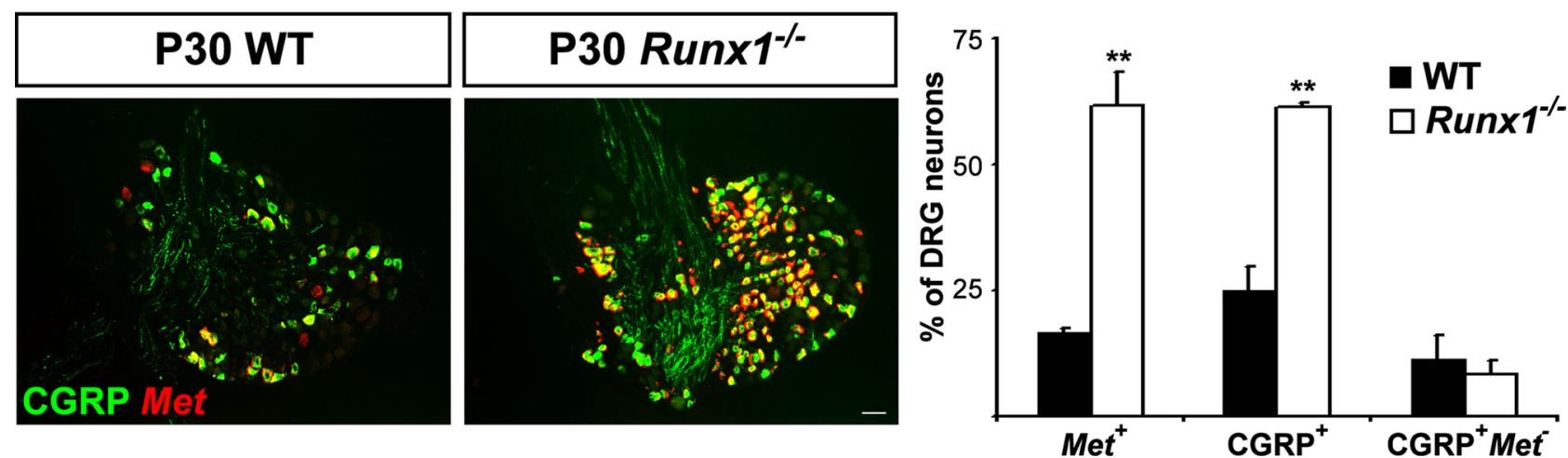

Figure 4. RUNX1 represses Metexpression in vivo. Met is derepressed in Runx $1^{-1-}$ DRG neurons. Representative pictures illustrating the increase of Met expression in DRG neurons in the absence of RUNX1. Quantitative analysis demonstrated that Metincrease in Runx $1^{-1-}$ mice was parallel to the expansion of CGRP population. Interestingly, the proportion of CGRP ${ }^{+}$Met $^{-}$neurons was not affected ${ }^{* *} p<0.001$, control, $n=3$; Runx $1^{-1-}, n=3$ ). Immunofluorescence for CGRP. In situ hybridization for Met. Scale bar, $50 \mu \mathrm{m}$.

$\left.\mathrm{MgCl}_{2}, 0.5 \% \mathrm{NP}-40\right)$ containing a protease inhibitor mix. After sonication, samples were centrifuged for $10 \mathrm{~min}$ at $10,000 \times g$ at $4^{\circ} \mathrm{C}$. The supernatant was removed and stored at $-80^{\circ} \mathrm{C}$. Fifty micrograms of protein was electrophoresed and then transferred to a nitrocellulose membrane in $25 \mathrm{~mm}$ Tris, $192 \mathrm{~mm}$ glycine, and 20\% ethanol. After blocking (for $1 \mathrm{~h}$ at room temperature in Tris buffer containing 5\% nonfat dried milk and $0.05 \%$ Tween-20), blots were incubated in primary mouse monoclonal antibody anti- $\alpha$-tubulin $1 / 10,000$ (Sigma) or rabbit polyclonal anti-human Met 1/500 (Santa Cruz Biotechnology) overnight at $4^{\circ} \mathrm{C}$. Membranes were rinsed three times, incubated with the appropriate horseradish peroxidase-linked sec- ondary antibody at 1/5000 (Jackson ImmunoResearch Laboratories) for $1 \mathrm{~h}$ at room temperature and developed using ECL reagents (PerkinElmer).

\section{Results}

A subpopulation of peptidergic neurons arise from the Runx1 lineage

Previous studies have proposed that Runxl downregulation is essential for a subpopulation of prospective nociceptors to undergo peptidergic differentiation (Chen et al., 2006; Woolf and Ma, 2007). 
However, experimental evidence showing that peptidergic CGRP ${ }^{+}$/ $\mathrm{TrkA}^{+}$neurons derive from the initial population of nociceptive precursors coexpressing RUNX1 and TrkA is still lacking. To examine this possibility, we performed a fate-mapping analysis using a recently developed tamoxifen-inducible Runxl-Cre knock-in mouse strain (Runx1 ${ }^{\text {Cre }}$ ) (Samokhvalov et al., 2007) crossed with reporter mice (Rosa26-loxP-STOP-loxP-eYFP) (Srinivas et al., 2001). To induce recombination, pregnant females received a single injection of 4-hydroxytamoxifen at three developmental time points: E11.5, E12.5, or E13.5. Using this system, and knowing that $\sim 88 \%$ of $\operatorname{TrkA}^{+}$neurons coexpress Runxl at E14.5 (Chen et al., 2006), we first evaluated the efficiency of recombination by monitoring the proportion of DRG neurons coexpressing TrkA and enhanced yellow fluorescent protein (eYFP) at birth. We found that pregnant mothers injected at E12.5 yielded the highest proportion of recombination in $\mathrm{TrkA}^{+}$neurons compared with the two other time points $(1.61 \pm 0.19 \%$ at $\mathrm{E} 11.5, n=2 ; 16.25 \pm 1.93 \%$ at E12.5, $n=5$; and $10.2 \pm 2.03$ at E13.5 $n=4)$. More importantly, we found a moderately high proportion of CGRP ${ }^{+}$neurons coexpressing eYFP $(10.3 \pm 1.9 \% ; n=5)$ (Fig. 1). Taking into account the recombination efficiency, the percentage of $\mathrm{CGRP}^{+}$neurons coexpressing eYFP rose to $50.0 \pm 6.7 \%$. These data provide the first in vivo evidence showing that a subset of $\mathrm{CGRP}^{+}$neurons (about one half) derives from $\mathrm{TrkA}^{+} / \mathrm{RUNX}^{+}$progenitors (Fig. 1).

\section{Met is expressed in a subset of DRG neurons}

Lineage-mapping experiments indicate that a subset of peptidergic neurons extinguish Runxl during development. In the search for factors that could participate in Runxl extinction, the HGFMet system was a particularly interesting candidate. Previous studies have reported the presence of Met in DRG (Maina et al., 1997; Funakoshi and Nakamura, 2001). More importantly, HGF has been shown to act synergistically with NGF both in DRG and superior cervical ganglia (SCG) neurons (Maina et al., 1997).

The expression pattern of Met in the somatosensory system has not hitherto been examined in detail. Using in situ hybridization, we found in adult thoracic DRG that Met is present in $\sim 19.4 \pm 2.6 \%$ of all DRG neurons. We then sought to determine whether Met expression was restricted to precise neuronal populations. We observed that $73.5 \pm 3.8 \%$ of Met neurons coexpress TrkA, indicating that $\mathrm{Met}^{+}$neurons mainly encompass peptidergic nociceptors (Fig. $2 a, b)$. In support of this hypothesis, we found an extensive overlap

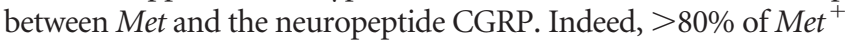
neurons coexpress CGRP and, conversely, $55.5 \pm 3.1 \%$ of the total number of CGRP ${ }^{+}$neurons coexpress Met (Fig. 2a,b).

We have also observed that Met is expressed in relatively few Ret $^{+}$neurons $(4.6 \pm 1.2 \%$ corresponding to $6.2 \pm 4.2 \%$ of $\mathrm{Met}$ neurons). Several lines of evidence suggest that $\mathrm{Met}^{+} / \mathrm{Ret}^{+}$neurons are not nociceptive but proprioceptive neurons. First, they are large-diameter neurons and represent $<5 \%$ of the total number of Ret-expressing neurons. Second, a significant proportion of $\mathrm{Met}^{+}$neurons are positive for proprioceptive markers such as parvalbumin $(\mathrm{PV})(18.1 \pm 5.3 \%)$ or $\operatorname{TrkC}(4.8 \pm 0.2 \%)$ (Fig. $2 a, b)$. Third, and more importantly, it seems that Met and Runx 1 have mutually exclusive expression patterns and are never expressed in the same neurons in the adult DRG (Fig. 2a). Finally, we showed that most, if not all, $\operatorname{Trk} B^{+}$putative mechanoceptive neurons are devoid of $\operatorname{Met}(1.2 \pm 0.9 \%)$.

We next examined the temporal expression pattern of Met in DRG. At E14.5, Met is mainly expressed in large neurons (supplemental Fig. 1a, available at www.jneurosci.org as supplemental material) and is coexpressed with PV (supplemental Fig. 1b, available at www.jneurosci.org as supplemental material). As de- a

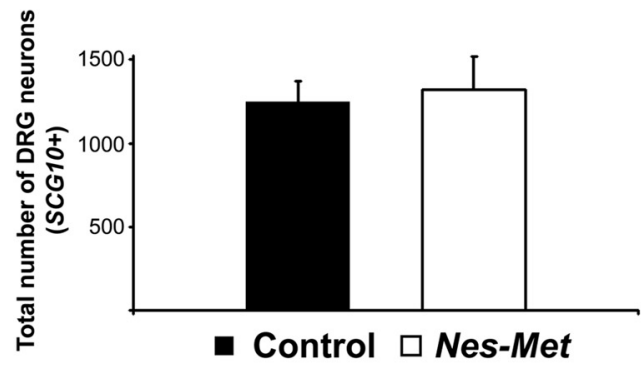

b
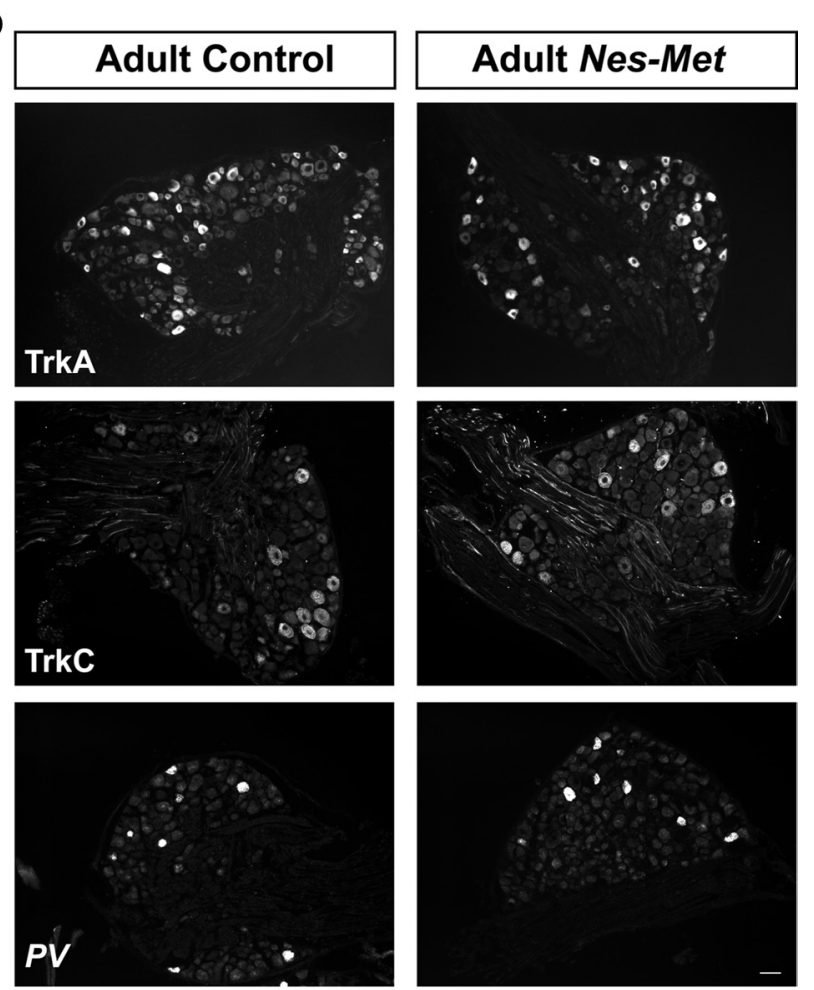

C

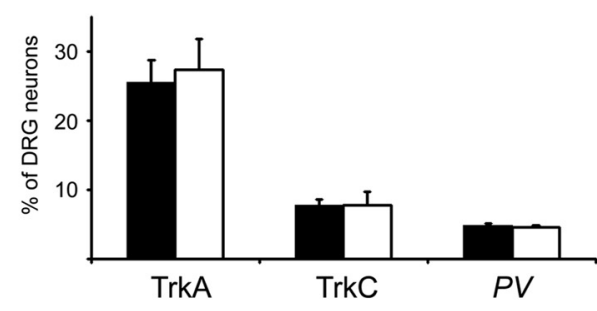

- Control $\square$ Nes-Met

Figure 5. Conditional Nes-Met mutants do not show defects in the number of neurons or early specification of nociceptive and proprioceptive neurons. $\boldsymbol{a}$, Quantification of DRG neurons using the pan-neuronal marker $S C G 10$ revealed no differences between Nes-Met and their control littermates (control, $n=3 ;$ Nes-Met, $n=3$ ). $\boldsymbol{b}$, Representative pictures illustrating the distribution of TrkA, TrkC, and PV-expressing neurons in control and NesMet DRG. Immunofluorescence for TrkA and TrkC. In situ hybridization for PV. C, Quantitative analysis of the numbers of DRG neurons positive for TrkA, TrkC, and PV showed no significant differences in Nes-Met mutants compared with control mice (control, $n=4$; Nes-Met, $n=4)$. Scale bars, $50 \mu \mathrm{m}$.

velopment proceeds, Met expression expands and starts to be detected in a subset of small-diameter $\mathrm{CGRP}^{+}$neurons (supplemental Fig. $1 c, d$, available at www.jneurosci.org as supplemental material).

We hypothesized that progressive expression of Met in a subset of CGRP ${ }^{+}$neurons might be the key event for Runx1 extinction in vivo. An absolute prerequisite to validate this hypothesis is 
Table 1. Quantitative analysis of molecular markers in wild-type and Nes-Met mice

\begin{tabular}{lccc}
\hline Markers & WT $(\%)(n=3)$ & Nes-Met $(\%)(n=3)$ & $p$ \\
\hline Ret & $48.62 \pm 1.64$ & $61.46 \pm 4.61$ & 0.02 \\
Runx1 & $34.29 \pm 1.38$ & $48.06 \pm 4.77$ & 0.019 \\
Mrgpra1 & $2.2 \pm 0.65$ & $2.01 \pm 0.32$ & n.s. \\
Mrgpra3 & $3.01 \pm 1.23$ & $2.88 \pm 1.12$ & n.s. \\
Mrgprd & $21.61 \pm 1.65$ & $20.27 \pm 2.83$ & n.s. \\
IB4 & $26.69 \pm 0.7$ & $25.71 \pm 9.13$ & n.s. \\
Trpm8 & $2.68 \pm 0.19$ & $2.46 \pm 0.81$ & n.s. \\
TrkC & $7.76 \pm 0.83$ & $7.81 \pm 2$ & n.s. \\
PV & $4.86 \pm 0.31$ & $4.67 \pm 0.22$ & n.s. \\
TrkA & $25.56 \pm 3.19$ & $27.32 \pm 4.4$ & n.s. \\
CGRP & $21.18 \pm 3.13$ & $11.06 \pm 2.32$ & $<0.01$ \\
Trpv1 high & $6.54 \pm 0.98$ & $3.77 \pm 0.38$ & 0.028 \\
Trpv1 total & $29.94 \pm 4.98$ & $29.65 \pm 3.55$ & n.s. \\
Trpa1 high & $4.69 \pm 0.37$ & $2.16 \pm 0.41$ & $<0.001$ \\
Trpa1 total & $40.43 \pm 6.38$ & $31.63 \pm 3.03$ & n.s. \\
SPhigh & $8.69 \pm 0.78$ & $14.06 \pm 2.17$ & 0.038 \\
SPtotal & $18.62 \pm 4.16$ & $22.04 \pm 4.44$ & n.s. \\
\hline
\end{tabular}

WT, Wild-type mice.
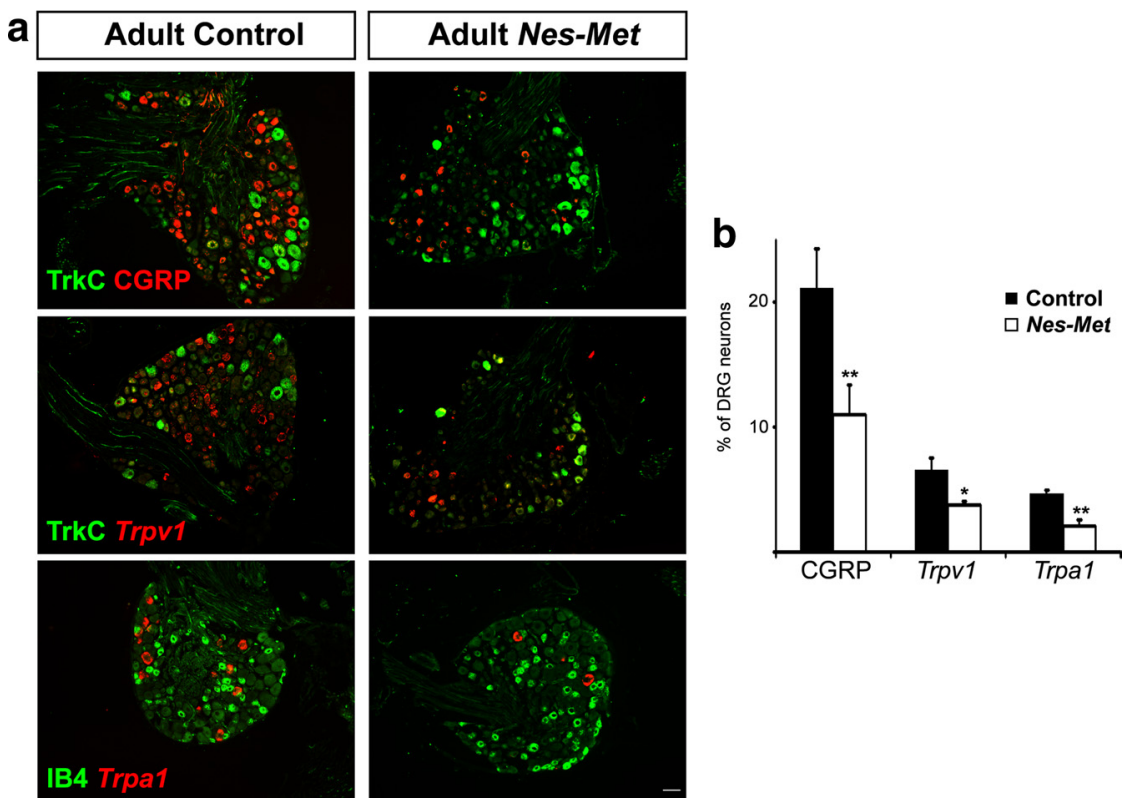

Figure 6. Disruption of peptidergic markers in Nes-Met mice. $\boldsymbol{a}$, Expression of the peptidergic markers CGRP, Trpv1, and Trpa1 in control and Nes-Met DRG. Immunofluorescence for CGRP, IB4, and TrkC. In situ hybridization for Trpv1 and Trpa1. b, Neuronal counts revealed that Met deletion led to a significant reduction in the number of DRG neurons expressing CGRP, Trpv1, and Trpa1 (control, $n=3$; Nes-Met, $n=3 ;{ }^{* *} p<0.01,{ }^{*} p<0.05$ ). Scale bar, $50 \mu \mathrm{m}$.

that both factors need to be coexpressed at a certain point during nociceptor development. To confirm the existence of this transient population, we took advantage of a previously described Runxl reporter mouse strain (Runx1 $1^{\text {LacZ }}$ ) (North et al., 1999). Consistent with our hypothesis, a number of RUNX1 ${ }^{+} \mathrm{Met}^{+}$ double-labeled neurons could be easily identified at E16.5 (Fig. $2 c$ ). These results suggest that the expression profile of Met is compatible with a potential role in Runxl extinction.

\section{Generation of Met conditional knock-out mice}

The specific expression pattern of Met in distinct DRG neuronal subpopulations prompted us to investigate the role of Met during the acquisition of primary sensory neuron identity. Embryos homozygous for the null allele of Met or for the signaling-dead Met ${ }^{d}$ allele die between E13.5 and E16.5 (Bladt et al., 1995; Maina et al., 1997). Moreover, an increased apoptotic rate had been measured in the DRG of Met ${ }^{d / d}$ embryos at E11.5-E12.5 (Maina et al., 1997). To circumvent potential survival defects and to uncover the in vivo role of Met during late maturation of DRG neurons, we generated a neuronal-restricted Met loss-of-function mouse model. Mice with a loxP-based conditional Met allele (Maina et al., 1998; Huh et al., 2004) were crossed with a Nestin-Cre mouse strain (Kramer et al., 2006a; Zhong et al., 2007). Met conditional knock-out mice $\left(\mathrm{Met}^{\mathrm{d} f \mathrm{fl} x}\right.$; Nestin-Cre, hereafter, referred to as $\mathrm{Nes}$-Met) are viable and fertile, grow at a normal rate, and show no obvious defects when compared with their Met ${ }^{d / f l x}$; Nestin$\mathrm{Cre}^{-}$littermates (hereafter, control).

To verify the efficiency of our conditional loss-of-function approach, Met transcripts levels in control and Nes-Met DRG were assessed at different developmental stages using quantitative RT-PCR (supplemental Fig. $2 a$, available at www.jneurosci.org as supplemental material). We observed no significant difference at E12.5. In contrast, the amount of Met mRNA declined markedly at E15.5 and reached very low levels in the adult Nes-Met DRG. Consistent with the absence of effect on Met expression at E12.5, we found no significant difference in the number of activated caspase 3-positive neurons between Nes-Met and control embryos (supplemental Fig. 2b,c, available at www.jneurosci.org as supplemental material). These results contrast with the significant increase in apoptosis seen in Met knock-out mice (Maina et al., 1997). Our data indicate that Cre expression under the control of Nestin promoter mediates effective loxP recombination in neurons well after the previously described period of cell death in the DRG (E10.5-E12.5) (Snider, 1994; White et al., 1996).

We next sought to investigate whether the efficiency of Nes-Cre recombination varied in a different subpopulation of DRG neurons. For that purpose, we crossed Nes-Cre animals with a reporter strain carrying a Rosa26 loxP-Stop-loxP-LacZ allele. Analysis of postnatal DRG (postnatal day 7 ) revealed that Cre-mediated recombination took place in the large majority of CGRP $^{+}$nociceptive neurons $(>80 \%$, $n=3$ ) (supplemental Fig. $2 c$, available at www.jneurosci.org as supplemental material). Altogether, our results showed that targeted inactivation of Met using the Nestin promoter to mediate cre recombination represents an appropriate strategy to investigate the role of $\mathrm{HGF} / \mathrm{Met}$ signaling in late nociceptive neuronal diversification.

\section{Met signaling controls Runx1 expression both in vivo and in vitro}

It has been shown that RUNX1 negatively regulates CGRP expression in vivo (Chen et al., 2006; Kramer et al., 2006b; Marmigère et al., 2006) and that Runxl expression is maintained through NGF signaling (Luo et al., 2007). One attractive hypothesis integrating all these data is that prospective nociceptors that respond only to NGF/TrkA signaling will maintain RUNX1, activate Ret, and adopt a nonpeptidergic fate, whereas those that respond to a signal emanating from the synergistic action of NGF and HGF would turn off Runxl, activate CGRP, and adopt a 
peptidergic fate. To explore this possibility, DRG cultures were transfected with a GFP-reporter vector alone or together with a plasmid driving human Met overexpression (supplemental Fig. 3 , available at www.jneurosci.org as supplemental material). Immediately after transfection, neurons were treated for $24 \mathrm{~h}$ with no growth factors, NGF (20 ng/ml), HGF (50 ng/ml), or a combination of NGF $(20 \mathrm{ng} / \mathrm{ml})$ and HGF $(50 \mathrm{ng} / \mathrm{ml})$, and the levels of Runx 1 were assessed by quantitative RT-PCR (supplemental Fig. 3, available at www.jneurosci.org as supplemental material). We found that although HGF alone did not modify Runx1 transcription, the combination of HGF and NGF led to a significant reduction of Runx 1 transcripts compared with NGF-treated cultures $(p<0.05)$ (supplemental Fig. 3, available at www. jneurosci.org as supplemental material). Overexpressing human Met in DRG neurons resulted in a more pronounced decrease of Runx1 levels in response to HGF $(p<0.05)$ (supplemental Fig. 3, available at www.jneurosci.org as supplemental material). Similar results were obtained in PC12 cells (data not shown). Together, these in vitro studies indicated that activation of the Met-signaling cascade interferes with TrkA-triggered Runx1 transcriptional regulation.

We next sought to examine whether repression of Runxl by Met signaling also occurs in vivo. For that purpose, we followed Runxl expression in Nes-Met mutants and control mice. We found that, at E15.5 and E18.5, the number of RUNX1 ${ }^{+}$neurons was similar in Nes-Met and control embryos (data not shown). In contrast, there was a significant increase in RUNX1 in the adult DRG $(34.3 \pm 1.4 \%$ in control and $48.1 \pm 4.8 \%$ in Nes-Met; $p=$ 0.019 ) (Fig. 3a). These observations strongly argue for a repressive effect of Met on Runx1 expression in vivo.

We hypothesized that if Met is necessary for Runxl extinction, then RUNX1 might persist in adult peptidergic $\operatorname{TrkA}^{+}$neurons in the Nes-Met mice. As expected, TrkA and RUNX1 are largely segregated in non-overlapping populations in control animals (Fig. $3 b$ ). In contrast, a number of $\operatorname{TrkA}^{+}$neurons coexpress RUNX1 in Nest-Met animals, demonstrating that Runxl extinction is impaired in the absence of Met. Altogether, these findings demonstrate that, in vivo, Met activity is required for proper extinction of Runxl in a subset of DRG sensory neurons.

\section{RUNX1 suppresses Met expression in vivo and in vitro}

We next sought to examine whether RUNX1 exerts a similar repressive effect on Met to ensure the generation of nonpeptidergic neurons. To verify this bidirectional regulation of Met and RUNX1, we examined Met expression in DRG of conditional Runx1 knock-out mice (Runx $1^{-/-}$) (Chen et al., 2006). We found a dramatic expansion of $\mathrm{Met}^{+}$neurons in Runx $1^{-1-}$ DRG $\left(16.8 \pm 0.7 \%\right.$ in control and $61.6 \pm 6.7 \%$ in Runx $1^{-1-} ; p<$ 0.001 ) (Fig. 4), which correlates with the previously described increase in the proportion of CGRP nociceptive neurons in Runx $1^{-1-}$ mice. These findings demonstrate that RUNX1 also represses Met in vivo and further supports the role of Met in regulating CGRP expression. Moreover, the proportion of CGRP neurons expressing Met was found to be significantly increased in Run $\times 1^{-/-}$compared with controls $(54.7 \pm 10.1 \%$ in control and $86.1 \pm 4.5 \%$ in Runx $\left.1^{-/-}, p<0.01\right)$. Interestingly, the number of $\mathrm{CGRP}^{+} \mathrm{Met}^{-}$neurons was not significantly altered (11.5 \pm $4.6 \%$ in control and $8.4 \pm 2.7 \%$ in Runx $1^{-1-}, p>0.35$ ) (Fig. 4), suggesting that the subset of peptidergic neurons that does not express Met (representing about one half of the CGRP ${ }^{+}$neurons in control mice) is not regulated by RUNX1. Finally, PC12 cells transfected with a plasmid driving human Runxl expression exhibited significantly lower levels of Met transcript compared with a

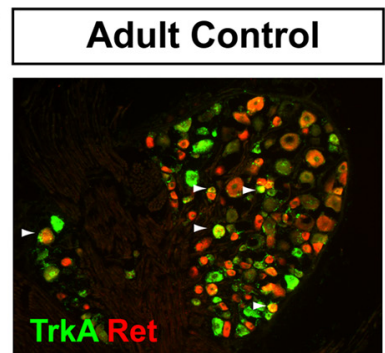

\section{Adult Nes-Met}
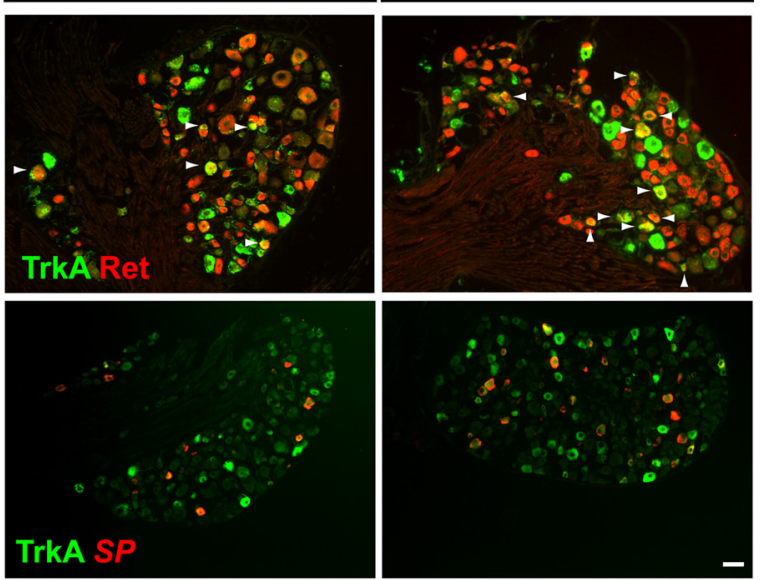

b
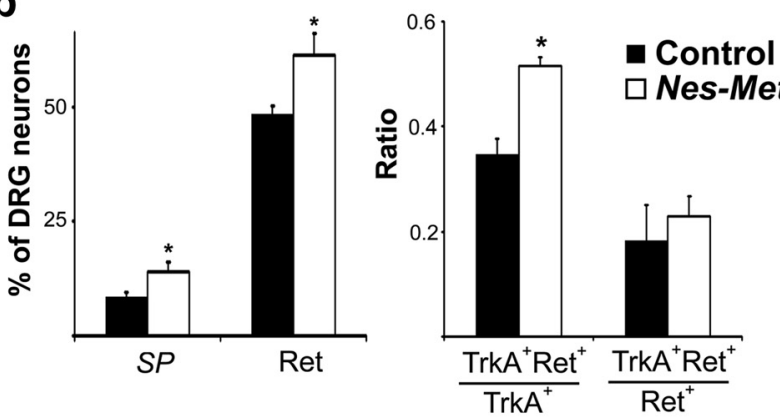

C

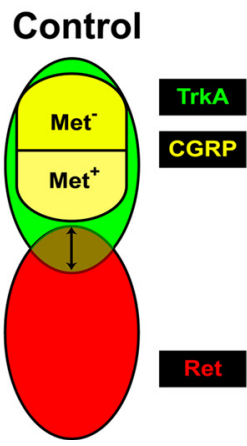

Nes-Met

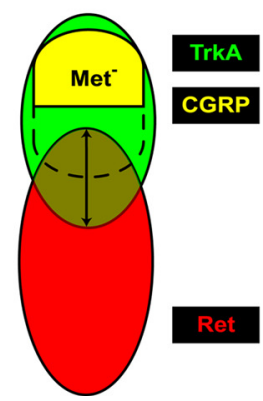

Figure 7. Phenotypic switch of nociceptive neurons in Nes-Met mice. $\boldsymbol{a}$, Double staining of TrkA/Ret and TrkA/SP showed an increase in the number of DRG neurons positive for Ret, $S P$, and TrkA/Ret (arrowheads) in Nes-Met mice. Conversely, TrkA remained unchanged. Immunofluorescence for TrkA and Ret. In situ hybridization for SP. $\boldsymbol{b}$, Quantitative analysis of the percentage of Ret and SP-expressing neurons (left) demonstrated a significant increase in Nes-Met DRG. The proportion of double-labeled $\mathrm{TrkA}^{+} /$Ret $^{+}$neurons is also augmented (right) (control, $n=4$; Nes-Met, $n=5 ; p<0.05$ ). c, Schematic representation of the observed defects of nociceptive maturation in Nes-Met mice. Briefly, a subset of prospective peptidergic CGRP ${ }^{+}$neurons is lost (dotted line) and switch their fate to become TrkA ${ }^{+} /$Ret $^{+}$neurons expressing SP. Scale bar, $50 \mu \mathrm{m}$.

GFP-transfected or naive PC12 cells (data not shown). Altogether, these findings demonstrate the impact of RUNX1 repressor activity on Met expression and the importance of a proper balance between RUNX1 and Met for the correct development of nonpeptidergic nociceptive neurons.

\section{Impaired maturation of a subset of peptidergic neurons in Nes-Met mice}

We next investigated the impact of Met loss of function on the molecular diversification of DRG neurons. We found similar DRG neuronal counts in adult Nes-Met and control mice (Fig. $5 a$ ), confirming that the trophic effect elicited by the HGF/Met 


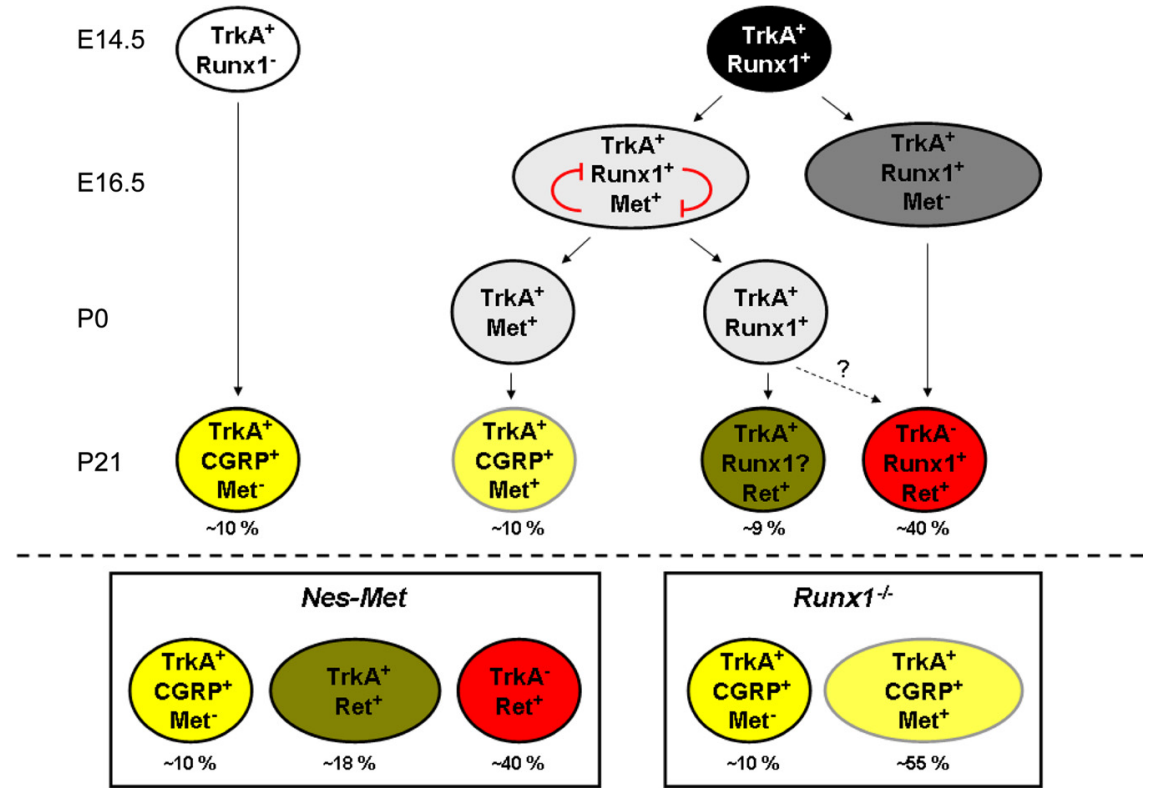

Figure 8. Proposed model for late maturation of nociceptive neurons. As described previously, prospective nociceptive neurons are TrkA ${ }^{+}$at E14.5. At this stage, most of these cells (88\%) coexpresses Runx 1 (right column), whereas only a minor population remains TrkA ${ }^{+}$Runx $1^{-}$(left column). Our findings suggest that this latter population give rise to a subset of CGRP ${ }^{+}$nociceptive neurons independently from Runx 1 and Met. According to our hypothesis, Runx1 high expressors would give rise to Ret $^{+}$nonpeptidergic neurons. Finally, low levels of Runx1 might allow initial Met expression and the apparition of a transitory population of $\mathrm{Met}^{+}$Runx $1^{+}$cells. Due to mutually repressive activity, this population would segregate and become either $\mathrm{Met}^{+} \mathrm{CGRP}^{+}$or $\mathrm{TrkA}^{+}$Ret $^{+}$neurons. Boxes in the lower part of the scheme represent the final distribution of different subsets of nociceptive neurons in the absence of Met (left) or Runx1 (right).

system is only confined to early DRG neurons developmental stages (Maina et al., 1997). We then assessed the different subpopulations of DRG neurons and found that expression of PV and TrkC remained unaffected (Table 1, Fig. 5b,c). Similarly, markers of nonpeptidergic nociceptive neurons such as IB4, $\mathrm{Mrg}$ pra1, Mrgpra3, or Mrgprd (Table 1) were not altered in Nes-Met animals. These results indicate that Met inactivation does not affect either proprioceptive or nonpeptidergic nociceptive neurons differentiation.

When we examined CGRP expression, on the other hand, we found it to be markedly reduced in Nes-Met mutants (Fig. 6a,b). In the adult thoracic DRG, CGRP is expressed in $21.2 \pm 3.1 \%$ of neurons, whereas this percentage is reduced to $11.1 \pm 2.3 \%$ in Nes-Met mice $(p<0.01)$. Accordingly, the dorsal horn of the spinal cord and the trunk skin showed decreased immunoreactivity to CGRP staining in Nes-Met mice, suggesting that less central and peripheral projections express this neuropeptide (supplemental Fig. $4 a, b$, available at www.jneurosci.org as supplemental material). However, staining with IB4 and the panneuronal marker PGP9.5 showed no differences between control and Nes-Met animals, suggesting that both central and peripheral axonal pathfinding occurs normally when Met is lost at late developmental stages.

We also found that the expression of other proteins specific to $\mathrm{CGRP}^{+}$nociceptive neurons is perturbed in Nes-Met animals. Previous studies have shown that TRPV1 is expressed in both peptidergic and nonpeptidergic neurons (Price and Flores, 2007), with peptidergic neurons being more responsive to capsaicin than nonpeptidergic neurons (Dirajlal et al., 2003). When we quantified the total number of $t r p v 1^{+}$neurons, we found no difference between control and Nes-Met mice (Table 1). Importantly, the percentage of neurons expressing high levels of trpv1 was significantly reduced in mutant mice (control $6.5 \pm 1 \%$;
Nes-Met $3.8 \pm 0.6 \% ; n=3 ; p=0.02$ ) (Fig. $6 a, b$, Table 1). Similarly, the total number of $\operatorname{trpa1} 1^{+}$neurons was found to be only moderately decreased in Nes-Met mice (Table 1), whereas the difference was significant for neurons expressing high levels of trpal (control, $4.7 \pm 0.4 \%$; Nes-Met, $2.2 \pm 0.4 \% ; n=4 ; p<0.001$ ) (Fig. $6 a, b$, Table 1). In agreement with these observations, we found that $\mathrm{Ca}^{2+}$ transients in response to capsaicin $(1 \mu \mathrm{M})$ or allylisothiocyanate $(1 \mu \mathrm{M})$ had significantly smaller amplitudes in DRG neurons from Nes-Met compared with control mice (data not shown). Interestingly, $\operatorname{TrkA}^{+}$ neuronal counts were not perturbed in the absence of Met $(25.6 \pm 3.2 \%$ in control vs $27.3 \pm 4.4 \%$ in Nes-Met). Together, these results indicate that the late maturation of peptidergic neurons is specifically impaired in Nes-Met mice.

\section{A subset of peptidergic neurons switches fate in the absence of Met}

We examined the molecular phenotype(s) adopted by the subset of presumptive $\mathrm{TrkA}^{+} / \mathrm{CGRP}^{+}$peptidergic neurons. Previous studies have shown that adult nociceptive neurons can be divided into the following three classes (Molliver et al., 1997; Woolf and Ma, 2007): TrkA $^{+}$peptidergic neurons; Ret ${ }^{+}$ nonpeptidergic neurons; and a poorly characterized subtype of neurons expressing both TrkA and Ret receptors. Unexpectedly, quantitative analyses showed that Nes-Met mutant animals displayed a significant increase in the proportion of Ret-expressing neurons $(48.6 \pm 1.6 \%$ in control and $61.5 \pm 4.6 \%$ in Nes-Met; $p=0.02$ ) (Fig. 7). Given that the proportion of TrkA ${ }^{+}$neurons was unchanged in Nes-Met mice, we next investigated whether a lack of Met signaling led to an expansion of the neuronal population coexpressing TrkA and Ret. Importantly, we found that the number of TrkA ${ }^{+} /$Ret $^{+}$neurons was doubled in Nes-Met mutants compared with control mice (control, $9.1 \pm 0.7 \%, n=3$; Nes-Met, $18.4 \pm 3.7 \%, n=3$ ). Moreover, when this proportion of $\mathrm{TrkA}^{+} / \mathrm{Ret}^{+}$neurons was normalized to the total number of TrkA $^{+}$or Ret ${ }^{+}$neurons, only the TrkA ratio was significantly increased $(p<0.05)$ (Fig. 4b). Thus, these results reveal a potential role of Met in nociceptive maturation before TrkA-Ret segregation. In addition, they indicate that loss of Met signaling drives a subset of peptidergic neurons from a TrkA ${ }^{+} / \mathrm{CGRP}^{+}$to a $\mathrm{TrkA}^{+} /$Ret $^{+}$molecular phenotype.

The population of $\operatorname{TrkA} A^{+} /$Ret $^{+}$neurons has not hitherto been described in detail. We therefore performed a number of triplestaining experiments to define molecularly this neuronal subtype and found the neuropeptide substance P (SP) to be of particular interest. SP has been previously described as a marker of peptidergic neurons (Marmigère and Ernfors, 2007). Nonetheless, our quantitative analysis demonstrated that $43.1 \pm 5.5 \%$ of $\operatorname{TrkA}^{+} /$ Ret $^{+}$neurons also express SP. As would be expected, we found that $S P$-expressing neurons were markedly increased in Nes-Met mutants compared with controls (Fig. 7b, Table 1).

The molecular switch from $\operatorname{TrkA}^{+} / \mathrm{CGRP}^{+}$to TrkA $^{+} /$Ret $^{+}$in Nes-Met mice suggests that CGRP expression may be regulated by Met in a subset of peptidergic neurons. To test this hypothesis, we 
followed the temporal expression pattern of CGRP in control and Nes-Met mice. At E15.5, a time point at which Met is not yet fully expressed in nociceptive neurons, we found no difference in the number of $\mathrm{CGRP}^{+}$neurons in Nes-Met compared with control embryos (supplemental Fig. 5, available at www.jneurosci.org as supplemental material). It is worth noting that at this same time point, CGRP just begins to be expressed in a subset of nociceptive neurons (Funakoshi et al., 2003; our unpublished observations). In contrast, a small, albeit significant, reduction of CGRPexpressing neurons was detected in Nes-Met embryos at E18.5 (supplemental Fig. 5, available at www.jneurosci.org as supplemental material). These findings perfectly correlate with the late onset and confinement of Met expression to a subset of CGRP ${ }^{+}$ neurons and raise the possibility that HGF-Met signaling regulates CGRP expression exclusively in these neurons.

\section{Discussion}

Here we report a novel mechanism for peptidergic specification involving a cross talk between RUNX1 and HGF-Met signaling. We provide compelling in vivo evidence that a cohort of nociceptive neurons acquires a peptidergic identity by using HGF-Met signaling in concert with NGF-TrkA to extinguish Runx1 and activate CGRP expression. Conversely, we also demonstrated that a second subset of peptidergic neurons mature independently of HGF-Met and RUNX1. Finally, we observed that persistent expression of RUNX1 is required for proper Met repression in prospective nociceptors undergoing nonpeptidergic differentiation. These data indicate that a balance between RUNX1 and Met is essential to determine nonpeptidergic versus peptidergic neuronal fate.

While intensive work has unraveled the transcriptional program driving nonpeptidergic maturation (Chen et al., 2006; Marmigère et al., 2006; Luo et al., 2007; Yoshikawa et al., 2007), little is known about the generation of peptidergic nociceptors. Our findings, obtained using four complementary mice models (Nes-Met, Runx $1^{-1-}$, Runx $1^{\text {Cre }}$, and Runx $1^{\text {LacZ }}$ ), indicate that peptidergic nociceptive neurons have a dual origin. Fatemapping analysis using Run $x 1^{\mathrm{Cre}}$ mice (Samokhvalov et al., 2007) provides strong in vivo evidence that a class of peptidergic neurons derive from a RUNX1 lineage. Data obtained from Nes-Met mice show that a subset of presumptive peptidergic nociceptors loses CGRP expression in the absence of Met. More importantly, a thorough examination of Run $x 1^{-/-}$DRG demonstrates that a fraction of peptidergic neurons $\left(\mathrm{CGRP}^{+} \mathrm{Met}^{-}\right)$remains unaffected in the absence of RUNX1 (representing 50\% of CGRP ${ }^{+}$ neurons in the wild type) arguing that half of the $\mathrm{TrkA}^{+} \mathrm{CGRP}^{+}$ neurons might be generated independently from Met and Runx1 (i.e., from TrkA ${ }^{+}$Runx $^{-}{ }^{-}$Met ${ }^{-}$precursors). Conversely, the other half could be modified in the absence of Met or RUNX1, indicating that it might arise from $\mathrm{TrkA}^{+} \mathrm{RUNX}{ }^{+} \mathrm{Met}^{+}$precursors. Finally, use of Runx $1^{\text {Lac } Z}$ transgenic mice allowed us to confirm the existence of a transient population of $\mathrm{TrkA}^{+} \mathrm{RUNX}^{+}{ }^{+} \mathrm{Met}^{+}$precursors, lending further support to the emerging theory of the dual origin of peptidergic neurons. Collectively, these data provide an additional aspect that highlights the exquisite refinement of nociceptive maturation.

Mechanisms controlling Runx 1 expression are still poorly understood (Marmigère and Ernfors, 2007; Woolf and Ma, 2007). Pioneering work from David Ginty's group has begun to unravel the molecular pathways responsible for RUNX1 maintenance in nonpeptidergic neurons (Luo et al., 2007). This study provided compelling evidence that NGF signaling is crucial for this process. In agreement with these results, we observed that NGF treatment seems to be required for Runxl expression in PC12 cells (data not shown). The findings reported here demonstrated not only that Runxl extinction is an active process necessary for peptidergic specification but also demonstrated that Met signaling is an essential player in these events. We showed that deletion of Met in the DRG resulted in a significant increase of RUNX1 ${ }^{+}$ neurons and therefore in a deficient peptidergic maturation. More importantly, we showed that RUNX1 is retained in TrkA ${ }^{+}$ neurons (Fig. 3b) from adult Nes-Met animals, indicating that Met is essential for proper extinction of Runxl. Additionally, primary cultures of DRG neurons treated with NGF and HGF exhibit lower levels of Runx1. Thus, our finding that HGF-Met contributes to Runxl extinction extends our understanding of the molecular control of Runxl expression.

Based on our in vivo and in vitro results, we propose the following model of late nociceptor specification (Fig. 8). Depending on Runxl expression, prospective nociceptive neurons can be divided into the following two classes (Chen et al., 2006): $\mathrm{RUNX}^{-}{ }^{-}$neurons and RUNX1 ${ }^{+}$neurons. According to our in vivo data, the first population of peptidergic nociceptors most likely derives from TrkA ${ }^{+}$RUNX1 $^{-}$neurons (Fig. 8, left column). The absence of RUNX1 repressor activity would allow NGFTrkA signaling to drive peptidergic differentiation as previously shown (Lindsay and Harmar, 1989; Freeland et al., 2000). This population probably accounts for the remaining $\mathrm{CGRP}^{+}$neurons in the Nes-Met mice, as well as for the population of $\mathrm{CGRP}^{+} \mathrm{Met}^{-}$neurons that is not modified in $\mathrm{Runx1^{-1- }}$ mice. Regarding neurons expressing RUNX1, several scenarios could be envisaged. In the first one, the final phenotype of these neurons might depend on RUNX1 levels. The large majority of these neurons express high levels of RUNX1 and would repress Met expression, becoming therefore nonpeptidergic neurons (Fig. 8, right column). In contrast, a small proportion of these same neurons will express RUNX1 at a level that is permissive for Met expression (Fig. 8, middle column). Given the mutually repressive activity of Met and RUNX1, nociceptors coexpressing these two factors might be transient and rapidly segregate either into $\mathrm{Met}^{+}$peptidergic (if Met signaling is strong enough to extinguish Runx1 expression) or into $\operatorname{TrkA}^{+} /$Ret $^{+}$neurons (if RUNX1 activity is strong enough to repress Met expression). An alternative hypothesis is that RUNX1 might change its transcriptional activity during development; at early stages, it might act as an activator (e.g., positively controlling Trp channels, Ret, and Met expression), whereas, later on, it might switch to a repressive state (e.g., negatively controlling CGRP), as previously shown for Mrg receptors (Liu et al., 2008). Finally, one could imagine that additional factors might participate in this process. Thus, access to HGF might limit Met activation to certain neurons and/or expression of distinct cofactors might differentially modulate RUNX1 activity.

Why is Runxl expression activated only in a subset of TrkA ${ }^{+}$ neurons? Prior work has revealed that nociceptive neurons are generated in three sequential waves (Ma et al., 1999; Maro et al., 2004; Kramer et al., 2006b; Marmigère and Ernfors, 2007). The first arises from neural crest progenitor cells expressing the transcription factor Neurogenin2 (Ngn2). The second one is dependent on Ngn 1 cells and gives rise to the majority of nociceptive neurons. Finally, the third wave derives from boundary cap cells known to be Krox $20^{+}$(Maro et al., 2004). It is well established that RUNX1 is restricted to Ngn1-derived neurons (Ma et al., 1999; Kramer et al., 2006b). Therefore, one attractive hypothesis is that nociceptive neurons arising from other sources $\left(\mathrm{Ngn}^{2+}\right.$ progenitors and/or boundary cap cells) might give rise to the population of TrkA ${ }^{+} / \mathrm{RUNX}^{-}$neurons. Analysis of RUNX1 in 
previously described Ngn mutants (Ma et al., 1999) might provide new insights into this issue.

Is this developmental diversification of peptidergic neurons functionally relevant? Electrophysiological recordings showed that DRG neurons exhibiting strong responses to capsaicin and cinnamaldehyde mainly belong to the peptidergic class of nociceptive neurons (Dirajlal et al., 2003; Story et al., 2003). Interestingly, absence of RUNX1 leads to the expansion of a peptidergic population, accompanied by the selective loss of Trpal and high levels of Trpv1 (Chen et al., 2006). These molecular findings nicely correlate with the decreased behavioral responses to cold stimulation and noxious heat in Runx $1^{-/-}$knock-out mice. Our observation that high levels, but not intermediate levels, of TRPV1/TRPA1 are also affected in an independent mouse model (Nes-Met) gives further support to this hypothesis.

Collectively, the data presented in this study indicate that Met signaling is crucial for at least two elements of peptidergic maturation: the extinction of Runxl and the activation of CGRP expression. In this context, the reciprocal repression described here for Met and RUNX1, as well as their subsequent segregation, provide an attractive mechanism for the late diversification of nociceptive neurons.

\section{References}

Bladt F, Riethmacher D, Isenmann S, Aguzzi A, Birchmeier C (1995) Essential role for the $\mathrm{c}$-met receptor in the migration of myogenic precursor cells into the limb bud. Nature 376:768-771.

Chen CL, Broom DC, Liu Y, de Nooij JC, Li Z, Cen C, Samad OA, Jessell TM, Woolf CJ, Ma Q (2006) Runxl determines nociceptive sensory neuron phenotype and is required for thermal and neuropathic pain. Neuron 49:365-377.

Dirajlal S, Pauers LE, Stucky CL (2003) Differential response properties of $\mathrm{IB}(4)$-positive and -negative unmyelinated sensory neurons to protons and capsaicin. J Neurophysiol 89:513-524.

Freeland K, Liu YZ, Latchman DS (2000) Distinct signalling pathways mediate the cAMP response element (CRE)-dependent activation of the calcitonin gene-related peptide gene promoter by cAMP and nerve growth factor. Biochem J 345:233-238.

Funakoshi H, Nakamura T (2001) Identification of HGF-like protein as a novel neurotrophic factor for avian dorsal root ganglion sensory neurons. Biochem Biophys Res Commun 283:606-612.

Funakoshi K, Goris RC, Kadota T, Atobe Y, Nakano M, Kishida R (2003) Prenatal development of peptidergic primary afferent projections to mouse lumbosacral autonomic preganglionic cell columns. Brain Res Dev Brain Res 144:107-119.

Huh CG, Factor VM, Sánchez A, Uchida K, Conner EA, Thorgeirsson SS (2004) Hepatocyte growth factor/c-met signaling pathway is required for efficient liver regeneration and repair. Proc Natl Acad Sci U S A 101:4477-4482.

Ibáñez CF, Ernfors P (2007) Hierarchical control of sensory neuron development by neurotrophic factors. Neuron 54:673-675.

Isaka F, Ishibashi M, Taki W, Hashimoto N, Nakanishi S, Kageyama R (1999) Ectopic expression of the bHLH gene Math1 disturbs neural development. Eur J Neurosci 11:2582-2588.

Kramer ER, Knott L, Su F, Dessaud E, Krull CE, Helmbacher F, Klein R (2006a) Cooperation between GDNF/Ret and ephrinA/EphA4 signals for motor-axon pathway selection in the limb. Neuron 50:35-47.

Kramer I, Sigrist M, de Nooij JC, Taniuchi I, Jessell TM, Arber S (2006b) A role for Runx transcription factor signaling in dorsal root ganglion sensory neuron diversification. Neuron 49:379-393.

Lewin GR (1996) Neurotrophins and the specification of neuronal phenotype. Philos Trans R Soc Lond B Biol Sci 351:405-411.

Lindsay RM, Harmar AJ (1989) Nerve growth factor regulates expression of neuropeptide genes in adult sensory neurons. Nature 337:362-364.

Liu Y, Yang FC, Okuda T, Dong X, Zylka MJ, Chen CL, Anderson DJ, Kuner $\mathrm{R}, \mathrm{Ma}$ Q (2008) Mechanisms of compartmentalized expression of Mrg class G-protein-coupled sensory receptors. J Neurosci 28:125-132.
Luo W, Wickramasinghe SR, Savitt JM, Griffin JW, Dawson TM, Ginty DD (2007) A hierarchical NGF signaling cascade controls Ret-dependent and Ret-independent events during development of nonpeptidergic DRG neurons. Neuron 54:739-754.

Ma Q, Fode C, Guillemot F, Anderson DJ (1999) Neurogenin1 and neurogenin2 control two distinct waves of neurogenesis in developing dorsal root ganglia. Genes Dev 13:1717-1728.

Maina F, Hilton MC, Ponzetto C, Davies AM, Klein R (1997) Met receptor signaling is required for sensory nerve development and HGF promotes axonal growth and survival of sensory neurons. Genes Dev 11:3341-3350.

Maina F, Hilton MC, Andres R, Wyatt S, Klein R, Davies AM (1998) Multiple roles for hepatocyte growth factor in sympathetic neuron development. Neuron 20:835-846.

Marmigère F, Ernfors P (2007) Specification and connectivity of neuronal subtypes in the sensory lineage. Nat Rev Neurosci 8:114-127.

Marmigère F, Montelius A, Wegner M, Groner Y, Reichardt LF, Ernfors P (2006) The Runx1/AML1 transcription factor selectively regulates development and survival of TrkA nociceptive sensory neurons. Nat Neurosci 9:180-187.

Maro GS, Vermeren M, Voiculescu O, Melton L, Cohen J, Charnay P, Topilko P (2004) Neural crest boundary cap cells constitute a source of neuronal and glial cells of the PNS. Nat Neurosci 7:930-938.

Molliver DC, Wright DE, Leitner ML, Parsadanian AS, Doster K, Wen D, Yan Q, Snider WD (1997) IB4-binding DRG neurons switch from NGF to GDNF dependence in early postnatal life. Neuron 19:849-861.

Moqrich A, Earley TJ, Watson J, Andahazy M, Backus C, Martin-Zanca D, Wright DE, Reichardt LF, Patapoutian A (2004) Expressing TrkC from the TrkA locus causes a subset of dorsal root ganglia neurons to switch fate. Nat Neurosci 7:812-818.

North T, Gu TL, Stacy T, Wang Q, Howard L, Binder M, Marín-Padilla M, Speck NA (1999) Cbfa2 is required for the formation of intra-aortic hematopoietic clusters. Development 126:2563-2575.

Patapoutian A, Reichardt LF (2001) Trk receptors: mediators of neurotrophin action. Curr Opin Neurobiol 11:272-280.

Ponzetto C, Bardelli A, Zhen Z, Maina F, dalla Zonca P, Giordano S, Graziani A, Panayotou G, Comoglio PM (1994) A multifunctional docking site mediates signaling and transformation by the hepatocyte growth factor/ scatter factor receptor family. Cell 77:261-271.

Price TJ, Flores CM (2007) Critical evaluation of the colocalization between calcitonin gene-related peptide, substance $\mathrm{P}$, transient receptor potential vanilloid subfamily type 1 immunoreactivities, and isolectin B4 binding in primary afferent neurons of the rat and mouse. J Pain 8:263-272.

Raible DW, Ungos JM (2006) Specification of sensory neuron cell fate from the neural crest. Adv Exp Med Biol 589:170-180.

Samokhvalov IM, Samokhvalova NI, Nishikawa S (2007) Cell tracing shows the contribution of the yolk sac to adult haematopoiesis. Nature 446:1056-1061.

Smeyne RJ, Klein R, Schnapp A, Long LK, Bryant S, Lewin A, Lira SA, Barbacid M (1994) Severe sensory and sympathetic neuropathies in mice carrying a disrupted Trk/NGF receptor gene. Nature 368:246-249.

Snider WD (1994) Functions of the neurotrophins during nervous system development: what the knockouts are teaching us. Cell 77:627-638.

Srinivas S, Watanabe T, Lin CS, William CM, Tanabe Y, Jessell TM, Costantini F (2001) Cre reporter strains produced by targeted insertion of EYFP and ECFP into the ROSA26 locus. BMC Dev Biol 1:4.

Story GM, Peier AM, Reeve AJ, Eid SR, Mosbacher J, Hricik TR, Earley TJ, Hergarden AC, Andersson DA, Hwang SW, McIntyre P, Jegla T, Bevan S, Patapoutian A (2003) ANKTM1, a TRP-like channel expressed in nociceptive neurons, is activated by cold temperatures. Cell 112:819-829.

White FA, Silos-Santiago I, Molliver DC, Nishimura M, Phillips H, Barbacid M, Snider WD (1996) Synchronous onset of NGF and TrkA survival dependence in developing dorsal root ganglia. J Neurosci 16:4662-4672.

Woolf CJ, Ma Q (2007) Nociceptors-noxious stimulus detectors. Neuron 55:353-364.

Yoshikawa M, Senzaki K, Yokomizo T, Takahashi S, Ozaki S, Shiga T (2007) Runx1 selectively regulates cell fate specification and axonal projections of dorsal root ganglion neurons. Dev Biol 303:663-674.

Zhong J, Li X, McNamee C, Chen AP, Baccarini M, Snider WD (2007) Raf kinase signaling functions in sensory neuron differentiation and axon growth in vivo. Nat Neurosci 10:598-607. 